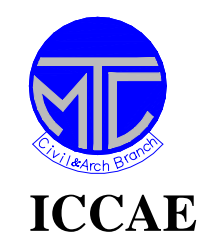

Military Technical College Kobry Elkobbah, Cairo, Egypt

\author{
6th International Conference \\ On Civil \& Architecture \\ Engineering
}

\title{
GUIDELINES FOR MAINTENANCE OF AIRPORT PAVEMENTS CASE STUDY: ASWAN INTERNATIONAL AIRPORT
}

\author{
S. EL-GIOSHY ${ }^{*}$, O. OSMAN ${ }^{* *}$, A. EL-DESOUKY ${ }^{*}$, S. FATALLA*
}

\begin{abstract}
Egypt has many airports which include millions of square meters of paved runways, taxiways and aprons, these pavements serve a great mix of different aircrafts. Aviation community has a large investment in airport pavements. The major objective in the design and construction of these pavements is to provide adequate load-carrying capacity and good ride-quality which permit safe operation of aircraft under all weather conditions. Immediately upon completion of construction, airport pavements begin a gradual deterioration which is attributed to several factors. These factors include traffic loads, weathering, and faulty construction technique. In addition inferior materials properties and differential movement the underlying subbase can fasten pavement deterioration, and effect pavement performance. Consequently, failure to perform routine maintenance during the early stages of deterioration may result in extensive repairs at a later date. The main objectives of this research were to provide guidelines for pavement maintenance periorites through the evaluation of pavement conditions. This objective was accomplished by performing a condition survey on Aswan International Airport as a case study to determine pavement distresses in accordance with ASTM D 5340-93. The computer software Micro PAVER 5.2 was then used to analyse the survey data. The Pavement Condition Index (PCI) was determined as an overall indicator for pavement condition. After that, the Forign Object Damage (FOD) and Structure Integiriry Capacity (SCI) were determined. Research results can be used to assist in identifying and forecasting maintenance and fuature repair work. consequantly periorites for conducting such this work can be assingned.
\end{abstract}

* Egyptian Armed Forces.

** Professor of Airport Engineering, Faculty of Engineering, Cairo University, Giza, Egypt. 


\section{KEY WORDS}

Airports, Flexible Pavements, Pavement Condition Index, and Distresses.

\section{INTRODUCTION AND LITERATURE REVIEW}

Aviation communities introduced new generations of aircraft having different weights, and performance. Like these generations raise the demand of developing a decision support system to keep all airfields in good conditions by evaluating airfield pavements for purpose of maintenance. The first step in determining the maintenance and rehabilitation (M\&R) of pavements is an accurate and comprehensive evaluation of their existing condition. The condition of an airfield pavement can be evaluated in terms of factors called condition indicators. Comprehensive pavement condition evaluation requires the measurement of these condition indicators which include operational surface indicators as roughness, skid resistance and potential for foreign object damage (FOD). Structural indicators like structural integirity and load carrying capacity can be also used as condition indicators. Figure (1) presents the major pavement condition indicators for airfield pavements. The figure also shows how the various distresses types in asphalt pavements relate to the various pavement condition indicators [1].

The gradual deterioration of a pavement occurs because of variation in climate and increasing traffic [2]. Through a systematic analysis of pavement life cycles a PMS can determine the most appropriate time to rehabilitate pavement, what is the most cost effective method is, and how many dollars it will take to maintain pavement at desirable condition level. In U.S.A., there are three methods for determining pavement condition: visual rating, nondestructive testing (NDT), and destructive testing. The visual rating

method is most commonly used, where all agencies are gathering information on their pavements based on a visual survey. However, the extent to which they gather the data varies. The NDT method is generally used for project level information to enhance visual ratings. NDT enables an agency to identify problems, examine their extent, and solve them effectively. A few agencies also use NDT data for network as well as project level evaluation. Destructive testing is primarily used to support design analysis in identifying Pavement makeup, reasons the Pavement failed, and solutions for improving the Pavament. This includes pavement coring, boring, and test pits, along with evaluation [3]. In this study visual rating method was used to identify pavement condtion where all pavements at AIA were divided into homogenous sections and assigned a section number as indices for assessing, storing, updating, and retrieving purposes [4].

\section{PAVEMENT CONDITION SURVEY}

A pavement condition survey is a visual inspection procedure for determining the present surface condition. The condition survey consists of inspecting a portion of the pavement surface for the various types of distresses, determining the severity of each distress, and measuring the density of each distress. The condition survey provides 
estimated density and severity of each distress type from which the PCI can be determined. The PCI is a numerical indicator based on a scale of 0 to 100 and is determined by measuring pavement surface distress that reflects the surface condition of the pavement. Pavement condition ratings (from excellent to failed) are assigned to different levels of numerical PCI values. These ratings and their respective PCI value definitions are shown in Figure (2). The distress types, distress severities, methods of survey, and PCI calculations are described in references [5,6]. Structural Condition Index (SCI), also known as $\mathrm{PCI}_{\mathrm{STR}}$, is the PCI obtained from considering only those distresses caused by structural deficiencies [7]. Because the PCI includes deducts due to non-structural deficiencies, it is difficult to judge the required overlay thickness based on a low PCI alone. In fact if most deficiencies are non-structural, the minimum recommended overlay thickness of 2 inches is typically adequate. The minimum acceptable value for the SCI is 35 [7], while Navy and Army have used a minimum SCI value of $50[8,9]$. A Foreign Object Damage (FOD) Index can be determined using the PCI survey data which is one of the primary factors for determining the serviceability of a pavement area. The FOD Index is determined from the PCI calculated by considering only the distresses/severity levels capable of producing FOD the FOD Index $=(100-$ PCIFOD). Figure (3) show the FOD Potential Rating Scale. The distresses cause the FOD includes Alligator Cracking, Block Cracking, Jet Blast Erosion, Joint Reflection Cracking, Longitudinal and Transverse Cracking, Oil Spillage, Patching, Raveling and Weathering, Shoving, and Slippage Cracking [10].

The PCI calculation procedure involves dividing a pavement into features which are defined as areas of pavement of like cross section subjected to similar traffic. Then each feature is divided into sample units to facilitate the inspection process. Sample units for AC pavements are approximately 465 sq. m. (5,000 sq. ft). A statistical sampling technique is often used to determine the required number of sample units to be surveyed to provide a specified confidence level in the results of the survey, as many sample units as possible were surveyed, generally 100 percent. After the sample units are inspected, the mean PCI of all the sample units within a feature is calculated and the feature is rated as to its condition: excellent, very good, good, fair, poor, very poor, and failed $[5,6,11]$. Inspection of all the pavement is not considered necessary, visual inspection is conducted on a selected number of samples of each pavement section each pavement section is divided into samples of manageable size [12].

\section{DISTRESS TYPES CLASSIFICATION}

A PCI survey is usually performed by measuring the amount and severity of certain defined distresses observed within a sample unit. There are sixteen different types of distress for flexible pavement [13]. These distresses include alligator cracking, bleeding, block cracking, corrugation, depression, jet blast, joint reflection cracking, longitudinal and transverse cracking, oil spillage, patching, polished aggregate, weathering, raveling, rutting, shoving, slippage cracking, and swelling. The main cause of most distresses is either load or weathering $[12,14,15]$. Load-related distresses exist where the pavement has been over-stressed by loads applied to its surface. Weathering-related distresses arise due to exposure to climatic conditions. Other related distresses are caused by actions not related to load or climate, such as fuel spills. Although each distress is 
assigned only one cause by the Micro PAVER software, the appearance and rate at which the distress occurs may be influenced by other causes. As an example, while Alligator cracking is caused by aircraft loads, its occurrence may be exacerbated by environmental factors. For instance, after prolonged wet weather, or during a spring thaw, the base course and sub grade materials may be significantly weaker than during dry weather. As a result, the occurrence of alligator cracking may be accelerated due to the fact that the asphalt concrete is flexing more under each aircraft load due to weak support conditions [15]. To obtain a reliable PCI for a given pavement section units within that section. An adequate number of randomly chosen sample units were selected for surveying based on the total number of sample units contained in the section,. The Advisory Circular recommends inspecting a specific number of sample units that will result in a confidence level in the data of 95 percent. It is not necessary to survey/inspect all samples [16]. Visual distress data are an excellent source of pavement condition information and are used in many ways by airfield pavement engineers, planners, and maintenance personnel. Pavement distress data are used to evaluate pavement performance and are a basic input to pavement management systems. The key to a useful pavement condition evaluation lies in the objectivity allowed and reliability of the survey procedures [17]. The PCI procedure, outlined in AFR 93-5 and further refined in ASTM Standard D5340, is used by the aviation industry to visually assess current airfield pavement condition.

\section{FEATURE IDENTIFICATION}

This section presents the feature identification of Aswan International Airport, as shown in Figure (4), as a case study to perform the visual inspection of pavement condition. According to the normal traffic types using the airfield and pavement type and construction, the main runway can be divided into 4 features paved using Polymer Modified Asphalt Concrete Pavement (PMA) as follows:

- Feature R01: This section starts from distance 0 to $200 \mathrm{~m}$ measured from the 17 Threshold. A total of 1 sample was inspected to represent the condition of this feature. The major distress types found in this feature are depression, longitudinal and transverse cracking, raveling and weathering.

- Feature R02: This section starts from distance 200 to $600 \mathrm{~m}$. A total of 3 samples were inspected to represent the condition of this feature. The major distress types observed in this feature are longitudinal and transverse cracking, depression, and block cracking.

- Feature R03: This section starts from distance 600 to $2800 \mathrm{~m}$ (runway interior). A total of 5 samples were inspected to represent the condition of this feature. The major distress types affecting this feature are longitudinal and transverse cracking, depression, and block cracking.

- Feature R04: This section starts from distance 2800 to $3402 \mathrm{~m}$ (35 touchdown zone). A total of 2 samples were inspected to represent the condition of this feature. The major distress types found in this feature are longitudinal and transverse cracking and depression.

According to the normal traffic types using the airfield and pavement type and construction, the taxiways could be divided into 6 features paved using Asphalt Concrete Pavement (AC) as follows: 
- Features T01A-T05A: Includes the whole length of the parallel taxiway "A". This taxiway is temporarily used as a runway. A total of 11 samples were inspected to represent the condition of all this features. The major distress types affecting this feature are longitudinal and transverse cracking, raveling and weathering, and block cracking.

- Feature T06B: Includes all connecting taxiways "C-F". A total of 4 samples were inspected to represent the condition of this feature. The major distress types affecting this feature are depression, polished aggregate, raveling and weathering, bleeding, and longitudinal and transverse cracking.

\section{STRUCTURAL INFORMATION}

For the main runway, major rehabilitation work of this runway was carried out in 2004 the work consisting of milling the top $10 \mathrm{~cm}$ of the old pavement and adding AC layers with $13.5 \mathrm{~cm}$ total thickness. Figure (5) presents an open pit shows the different structural layers of main runway. These layers are $7 \mathrm{~cm}$ macadam layer (bituminous gravel), old asphalt layers, old concrete pavement (tow layer), and prepared subgrade with $\mathrm{CBR} \geq 20 \%$. On the other hand, for main taxiway, major rehabilitation work was carried out in 2000 . The work consisting of milling the top $5 \mathrm{~cm}$ of the old pavement and adding AC layers with $12 \mathrm{~cm}$ total thickness. Figure (6) presents an open pit shows the different structural layers of the main taxiway which consists of $5 \mathrm{~cm}$ HMA surface course, $7 \mathrm{~cm}$ macadam layer, old Asphalt layers, old Concrete pavement, prepared subgrade with $\mathrm{CBR} \geq 20 \%$.

\section{DISTRESS ANALYSIS FOR ASWAN INTERNATIONAL AIRPORT}

Visual inspection was performed in May 2005. Table (1) presents the average values of PCI, PCI rating, SCI, and FOD while Table (2) introduces a summary of distress distribution for flexible pavements Table (3) introduces a summary of main causes of distresses. Based on results shown in these tables the following can be noticed:

- Feature R01: from Figure (7) the higher deduct point is $61.34 \%$ and $18.55 \%$ for depression and longitudinal and transverse cracking respectively so, the depression is the most serious distress appears in this feature, main cause of these distresses is "others".

- Feature R02: the higher deduct point is $41.81 \%$ and $34.78 \%$ for depression and longitudinal and transverse cracking respectively so, the depression is the most serious distress appears in this feature, main cause of these distresses "climatic/durability".

- Feature R03: the higher deduct point is $47.5 \%$ and $36.09 \%$ for longitudinal and transverse cracking and depression respectively so, the longitudinal and transverse cracking is the most serious distress appears in this feature, main cause of these distresses "climatic/durability".

- Feature R04: the higher deduct point is $43.2 \%$ and $42.67 \%$ for depression and longitudinal and transverse cracking respectively so, the depression is the most serious distress appears in this feature, main cause of these distresses "others". 
The survey was re-conducted in December 2005 and the results were reported in Tables $(4,5)$ where:

- Feature R01: from Figure (8) the higher deduct point is $42.49 \%$ and $27.78 \%$ for depression and longitudinal and transverse cracking respectively so, the depression is still the most serious distress appears in this feature, Main cause of these distresses is "Climatic/Durability".

- Feature R02: the higher deduct point is $36.15 \%$ and $27.04 \%$ for longitudinal and transverse cracking and depression respectively so, the depression is the most serious distress appears in this feature, main cause of these distresses "Climatic/Durability".

- Feature R03: the higher deduct point is $38.45 \%$ and $27.83 \%$ and $19.39 \%$ for longitudinal and transverse cracking, depression and block cracking respectively so, the longitudinal and transverse cracking is the most serious distress appears in this feature, main cause of these distresses "Climatic/Durability".

- Feature R04: the higher deduct point is $40.64 \%$ and $34.53 \%$ for depression and longitudinal and transverse cracking respectively so, the depression is the most serious distress appears in this feature, Main cause of these distresses "Climatic/Durability".

For the whole Runway: the average PCI of the whole area dropped from 59\% in May 2005 to $51 \%$ in December 2005 see Figure (9) the most influence distresses are caused by "Climatic/Durability" and "construction materials" had almost the same share in the contribution in the causes of the observed distresses. In December 2005 "climatic/durability" had a share of almost $70 \%$ indicating a rapid drop in condition due to the environmental effects on the pavement surface during the same period, the FOD index increased from 26 to 36 indicating a rapid increase in the potential of foreign object damage to aircrafts using this runway if opened to air traffic (overall condition rating changed from "almost none to minor FOD potential" to "minor FOD potential" within 6 months) as shown in Figure (10). Also from Figure (11) we see that there is no change in the values of SCI it means that most of the increased distresses is related to weathering. Figure (12) show summary of distress distribution by quantity for all features.

The Survey was conducted once on taxiways in May 2005. The results of this survey are also presented in Tables (1-3). The tables show that, the dominant distresses on Feature T01A are depression, and polished aggregate. Main cause of these distresses is "others". For Feature T02B the dominant distress is depression. Main cause of these distresses is "others". For Feature T03C, Feature T04B, Feature T05A, and Feature $\mathrm{T} 06 \mathrm{~B}$, the dominant distresses are (depression, and longitudinal and transverse cracking), (block cracking, and depression), (depression, block cracking and longitudinal and transverse cracking), and (depression), respectively. The main causes of these distresses are climatic/durability for the first three features and other for the last feature as shown in Figure (13). 


\section{OVERALL EVALUATION OF PAVEMENT CONDITION}

Main Runway 17-35 is in FAIR condition. This Runway is surfaced using PMA layer in 2004, some scattered areas along the runway are rated as "Poor" and "Satisfactory". Runway interior (600-2800 meters) seems to be in the worst condition this relatively bad condition is basically due to the poor quality of the recently applied maintenance work. The 17 Threshold side seems to be in better condition than Runway interior. In general, depression is the most serious distress covering the whole length of the runway. These depressions are built-up during construction rather than due to the settlement of the foundation soil (bad leveling both in the longitudinal and transverse directions). Longitudinal and transverse cracking is another serious distress observed along the runway with higher density and severity the cause of this distress is due to poorly constructed paving lane joints and poorly compaction at the edge of longitudinal paving lanes and can be reflect up from the edges and longitudinal cracking of an underlying old pavement, cracks with fragmented edges are common. All these cracks are due to environmental effects on the poorly constructed asphalt overlay. Medium severity block cracking (interconnected cracks that divide the pavement into approximately rectangular pieces) is another serious distress observed along the runway with low density and severity which start from about $150 \mathrm{~m}$ from 17 Threshold. This distress is related to the use of asphalt cement which has become too stiff for the climate and caused by the shrinkage of the asphalt concrete in response to low temperatures and progress from the surface of the pavement downward and asphalt binder hardening due to aging (possibly during mix preparation). Few of the observed cracks are spalled (pavement is fragmented along a crack).

Main Taxiway (Secondary Runway 17-35) is in "Fair" condition. However, a clear contrast in condition exists with sections in "Poor" condition near the south end of the taxiway and other sections in "Satisfactory" condition near the north end. Depression is the main distress type affecting the main taxiway. Low severity depression can be observed all over the taxiway with higher densities near the south end. Medium to low severity longitudinal/transverse cracking and low severity block cracking can be observed at some areas of the taxiway. Block cracking is more dominant near the south end of the taxiway from distance $2500 \mathrm{~m}$ to $3400 \mathrm{~m}$ measured from the 17 Threshold. Low severity polished aggregate and raveling were also observed at scattered areas along the taxiway. Polished aggregate, i.e., surface with no rough or angular aggregate particles to provide good skid resistance, is caused by repeated traffic applications near the 17 Threshold. Raveling is in the form of wearing away of the pavement surface caused by the dislodging of aggregate particles and loss of asphalt binder. This may indicate that the asphalt binder has hardened significantly due to aging and environmental factors. The reasons of the other distresses are as discussed above.

The connecting taxiways between the main runway and main taxiway are in "Poor" condition. A depression is the most dominant and effective distress type observed along these connecting taxiways. Low severity bleeding, raveling and weathering and Low to medium severity longitudinal and transverse cracking are also common. The reasons of the observed distresses are as discussed above. 


\section{CONCLUSIONS AND RECOMMENDATIONS}

Based on the analysis of data collected from Aswan International Airport, the following can be concluded:

1) The Pavement Condition Index, Foreign Object Damage, and Structure Condition Index, are valuable tools for making a decision for airport's pavement maintenance.

2) A detail pavement data base was developed in this study on the basis of grouping pavement sections having similar conditions and traffic and listing them as features.

3) The study presents the main distresses which appear in Egyptian airfields, and its effect on pavement performance.

4) The study show that the distresses related to load has the least appearance in airfield pavement.

5) The most distresses, appears in flexible pavement are caused by the effect of "Climate/Durability" and others but the "Climate/Durability" had almost the same share in the contribution in the causes of the observed distresses.

6) The distresses that have great effect on surface condition for flexible pavement are: Depression, block cracking, longitudinal and transverse cracking

7) Depression and unevenness of pavement surface could be explained by the poor leveling of the asphalt layers. This condition will definitely cause frequent pilot complaints and possible fatigue damage to aircrafts. Segregation of mix and subsequent pavement surface raveling and weathering is another type of pavement damage this distress form weak areas in the pavement top layer where further cracking is likely to develop.

8) Cracking of the main runway surface is mainly caused by the poor performance of the top polymer modified asphalt layer and the poor construction work.

In addition of the main conclusions, it is recommended to:

1) Establish a data base for all airfields to support the decision maker for maintenance of airport pavement.

2) Periodically updating of the inventory should be carried out for the same features which have been surveyed before.

3) Developing the design mix to obtain a new mix having a good factor of safety to resist all climate condition in Egypt and fulfils all the design requirements.

4) Introducing additional technical provisions for the used equipments and given more attention to use automatic levels adjustment aids.

\section{REFERENCES}

[1] M.I.D. M.Y. Shahin, and S. Kohn, "Evaluation of Airfield Pavement Condition and Determination of Rehabilitation Needs", TRB, Transportation Research Record 700, 1979.

[2] S. El-gioshy, "Evaluation and Maintenance Management of Airfield Pavements", Master Thesis, Cairo University, Egypt, 1997.

[3] T.P.M.S.G.R. Team, "A guide for Local Agency Pavement Managers", December 1994.

$$
r . .
$$


[4] "An over view of Mn/DOT's "Pavement Condition Rating Procedure and Indices", Internet Site, accessed in March 2003.

[5] M.Y. Shahin, "Pavement Management for Airports, Roads, and Parking Lots", Chapman \& Hall, 1994.

[6] M.Y. Shahin, "Airfield Pavement Distress Measurement and Use in Pavement Management", Washington, 1982.

[7] MIL-HDBK-1021/4., "Rigid Pavement Design for Airfields", Military Handbook, Naval Facilities Engineering Command, Washington, April 1987.

[8] D. Alexander, "Nondestructive Procedures for Airfield Pavement Evaluation", Technical Manual, U.S. Army Corps of Engineers, Waterways Experiment Station, December 1994.

[9] D. Alexander, "Layered Elastic Evaluation Program - LEEP", User's Guide, U.S. Army Corps of Engineers, Waterways Experiment Station, Vicksburg, December 1994.

[10] AFCESA, "Engineering Technical Letter (ETL) 04-9: Pavement Engineering Assessment (EA) Standards", April 2004.

[11] M.T.A.C. Tsuru, G.D., "Airfield Pavement Condition Survey", Former NAS Barbers Point (Kalaeloa Airport), Oahu, Hawaii, Pacific Division, Naval Facilities Engineering Command, February 2004.

[12] V.A.A.V. Franz Alexander, "Development and Visualization of Airport Pavement Management Information", Transportation Research Board, 77th Annual Meeting, Washington, D.C., November, 1998.

[13] S. El-gioshy, "Development of Airport Pavement Condition Criteria Based on Runway / Aircraft Interaction.", Ph.D. Thesis, Cairo University, Egypt, 2001.

[14] E.R.A .D.C.E. "MicroPAVER- A Pavement Management System, Version 5.2 User's Guide", U.S. Army Corps of Engineers, Construction Engineering Research Laboratory (CERL), Champaign, Illinois, United States Government, 2004.

[15] I. Champaign, "Development of a Pavement Maintenance Management System", Volume II: Airfield Pavement Distress Identification Manual, Construction Engineering Research Laboratory, Report No. CEEDO TR 7744 VOL 2, December 1977.

[16] U.S.D.O.T. Federal Aviation Administration(FAA), "AC 150/5380-6, Guidelines and Procedures for Maintenance of Airport Pavements", Washington, D.C, December1982.

[17] L.J.M.G.D. Cline, C.J. Schiavino, NFESC; "Airfield Pavement Evaluation Former", NAS Barbers Point", (Kalaeloa Airport) Oahu, Hawaii March 2004. 
Table (1): Summary of Pavement Condition by Feature.

\begin{tabular}{|c|c|c|c|c|c|c|}
\hline \multirow{3}{*}{ Element } & Feature ID & Pavement Type & PCI & FOD & SCI & Rating \\
\hline \multirow{5}{*}{ Runway } & R01A & AC & 57 & 18 & 71 & FAIR \\
\cline { 2 - 7 } & R02B & AC & 68 & 22 & 82 & FAIR \\
\cline { 2 - 7 } & R03C & AC & 52 & 34 & 70 & POOR \\
\cline { 2 - 7 } & R04B & AC & 61 & 21 & 77 & FAIR \\
\cline { 2 - 7 } & ALL AC & AC & 59 & 26 & 75 & FAIR \\
\hline \multirow{7}{*}{ Taxiway } & T01A & AC & 72 & 6 & 82 & Satisfactory \\
\cline { 2 - 7 } & T02B & AC & 78 & 4 & 82 & Satisfactory \\
\cline { 2 - 7 } & T03C & AC & 51 & 31 & 68 & POOR \\
\cline { 2 - 7 } & T04B & AC & 55 & 36 & 73 & POOR \\
\cline { 2 - 7 } & T05A & AC & 53 & 29 & 73 & POOR \\
\cline { 2 - 7 } & T06B & AC & 49 & 11 & 55 & POOR \\
\hline
\end{tabular}

Table (2): Summary of Distress Distribution for Flexible Pavements.

\begin{tabular}{|c|c|c|c|c|c|c|c|c|c|c|}
\hline \multirow{2}{*}{ Distress Type } & \multicolumn{9}{|c|}{ \% of TDV for Element/Feature } \\
\cline { 2 - 13 } & \multicolumn{3}{|c|}{ Runway } & & \multicolumn{5}{c|}{ Taxiway } \\
\cline { 2 - 12 } & R01 & R02 & R03 & R04 & T01A & T02B & T03C & T04B & T05A & T06B \\
\hline Corrugation & & 1.59 & & & & & & & & \\
\hline Bleeding & & & & & & & 0.61 & & 14.98 & 9.05 \\
\hline Block Cracking & & 13.98 & 14.91 & 8.27 & & & 15.8 & 42.54 & 25.48 & \\
\hline Depression & 61.34 & 41.81 & 36.09 & 43.2 & 52.69 & 79.82 & 86.44 & 37.36 & 36.42 & 66.57 \\
\hline Oil Spillage & 4.3 & & & & & & & & 1.75 & \\
\hline L/T Cracking & 18.55 & 34.78 & 47.5 & 42.67 & 8.47 & 20.18 & 31.51 & 20.1 & 19.97 & 3.99 \\
\hline Patching & 4.3 & 2.39 & & & & & & & & \\
\hline Polished Aggregate & & & & & 30.38 & & & & & 6.58 \\
\hline Raveling and Weathering & 11.51 & 5.46 & 1.5 & 5.86 & 8.46 & & 8.86 & & 1.39 & 13.81 \\
\hline
\end{tabular}

Table (3): Summary of Cause of Distresses by Feature.

\begin{tabular}{|c|c|c|c|c|c|}
\hline \multirow{2}{*}{ Element } & \multirow{2}{*}{ Feature ID } & \multirow{2}{*}{ Pavement Type } & \multicolumn{3}{|c|}{ \% Deduct Points by Main Cause of Distress } \\
\hline & & & Load & Climate/Durability & Others \\
\hline \multirow{5}{*}{ Runway } & R01 & $\mathrm{AC}$ & 0 & 31 & 69 \\
\hline & R02 & $\mathrm{AC}$ & 0 & 53 & 47 \\
\hline & R03 & $\mathrm{AC}$ & 0 & 65 & 35 \\
\hline & R04 & $\mathrm{AC}$ & 0 & 48 & 52 \\
\hline & ALL AC & $\mathrm{AC}$ & 0 & 54 & 46 \\
\hline \multirow{6}{*}{ Taxiway } & T01A & $\mathrm{AC}$ & 0 & 19 & 81 \\
\hline & T02B & $\mathrm{AC}$ & 0 & 20 & 80 \\
\hline & T03C & $\mathrm{AC}$ & 0 & 56 & 44 \\
\hline & T04B & $\mathrm{AC}$ & 0 & 63 & 37 \\
\hline & T05A & $\mathrm{AC}$ & 0 & 47 & 53 \\
\hline & T06B & $\mathrm{AC}$ & 0 & 16 & 84 \\
\hline
\end{tabular}


Table (4): Summary of Pavement Condition by Feature Surveyed in December 2005.

\begin{tabular}{|c|c|c|c|c|c|c|}
\hline \multirow{2}{*}{ Element } & \multirow{2}{*}{ Feature ID } & \multirow{2}{*}{ Pavement Type } & \multicolumn{3}{|c|}{ Pavement Condition } & \multirow{2}{*}{ Rating } \\
\cline { 3 - 7 } & & & PCI & FOD & SCI & \\
\hline \multirow{5}{*}{ Runway } & R01 & AC & 54 & 30 & 71 & POOR \\
\cline { 2 - 7 } & R02 & AC & 59 & 33 & 82 & FAIR \\
\cline { 2 - 7 } & R03 & AC & 43 & 45 & 70 & POOR \\
\cline { 2 - 7 } & R04 & AC & 56 & 31 & 75 & FAIR \\
\cline { 2 - 7 } & ALL AC & AC & 51 & 36 & Poor \\
\hline
\end{tabular}

Table (5): Summary of Distress Distribution by Cause for All Features Surveyed in December 2005.

\begin{tabular}{|c|c|c|c|c|c|}
\hline \multirow{3}{*}{ Element } & \multirow{2}{*}{ Feature ID } & \multirow{2}{*}{ Pavement Type } & \multicolumn{3}{|c|}{ \% Deduct Points by Main Cause of Distress } \\
\cline { 4 - 6 } & & & Load & Climate/Durability & Others \\
\hline \multirow{4}{*}{ Runway } & R01 & & 0 & 56 & 44 \\
\cline { 2 - 6 } & R02 & & 0 & 72 & 28 \\
\cline { 2 - 6 } & R03 & & 0 & 72 & 28 \\
\cline { 2 - 6 } & R04 & & 0 & 52 & 38 \\
\cline { 2 - 6 } & ALL AC & & 0 & 67 & 33 \\
\hline
\end{tabular}

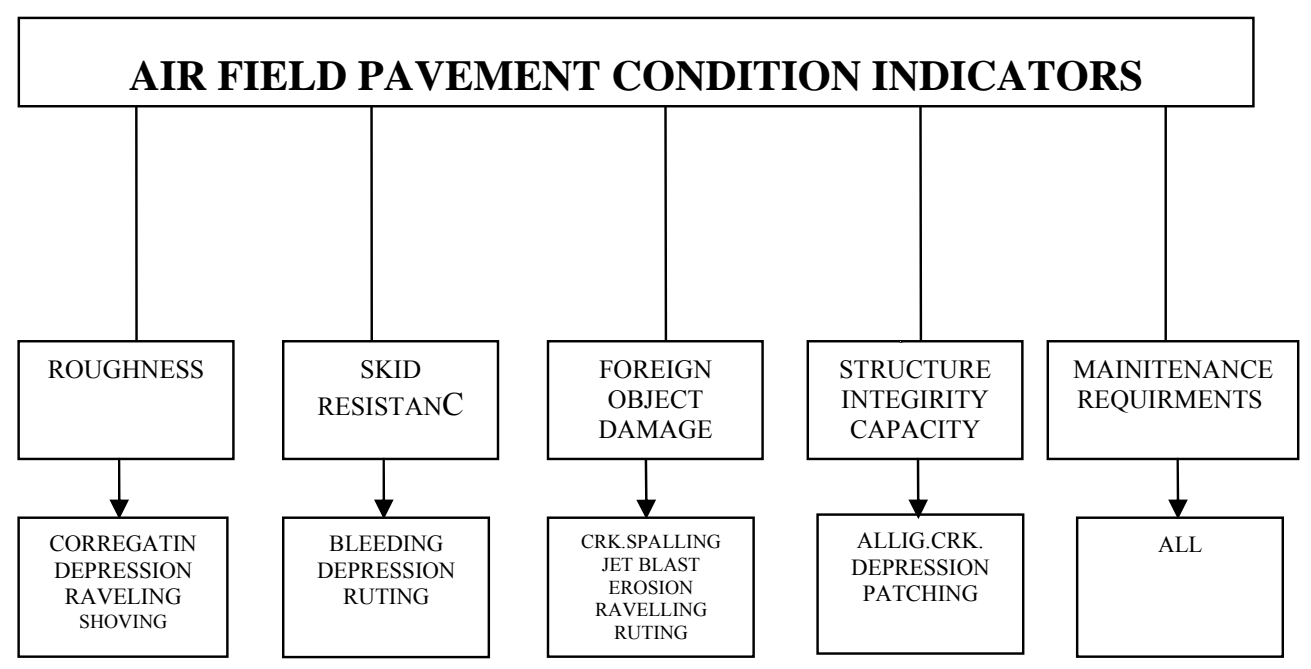

Figure (1): Relation between Pavement Condition Indicators and Distress Types for Asphalt Airfield Pavement [2]. 


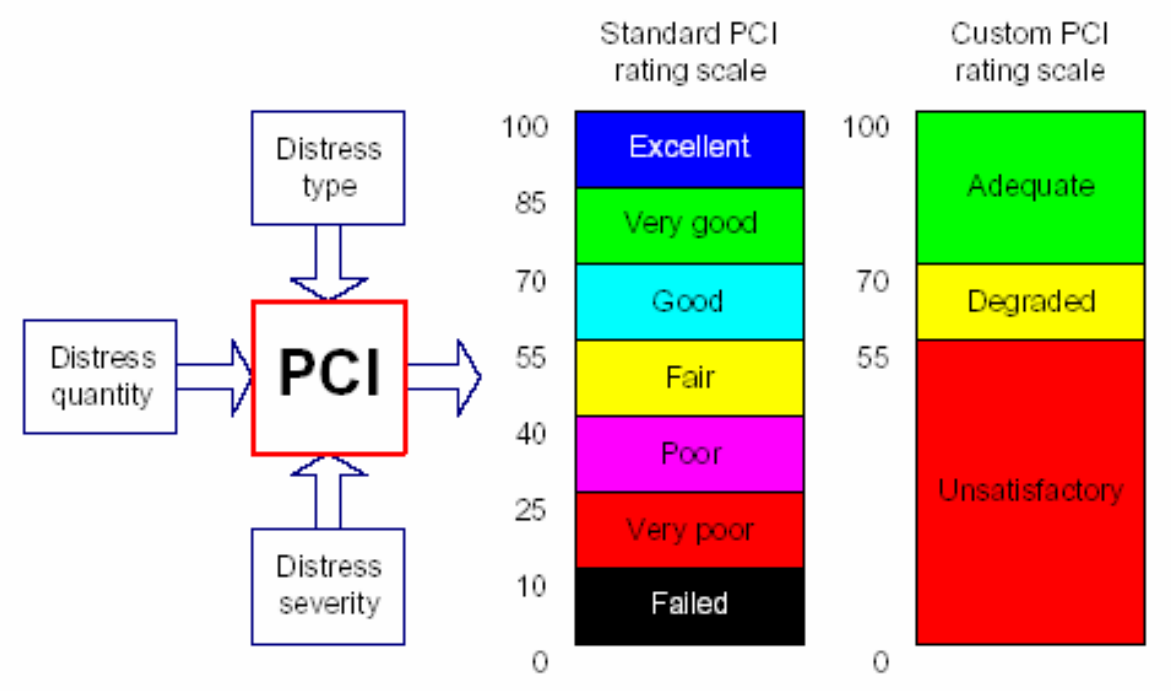

Figure (2): Pavement Condition Index Numerical Value versus Condition Rating [16].

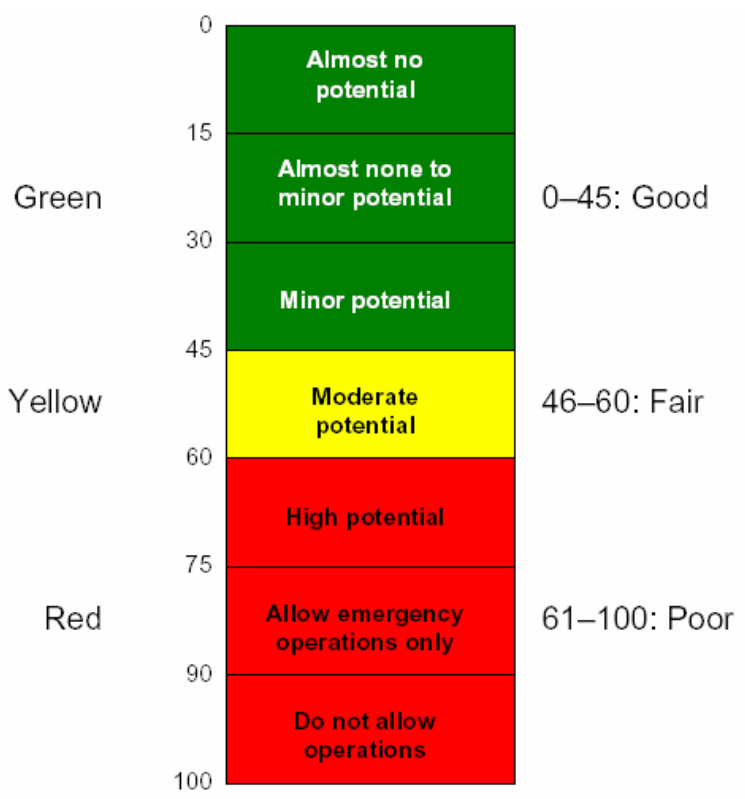

Figure (3): FOD Potential Rating Scale. 


\begin{tabular}{|l|l|}
\hline GE5 & $r .0$ \\
\hline
\end{tabular}

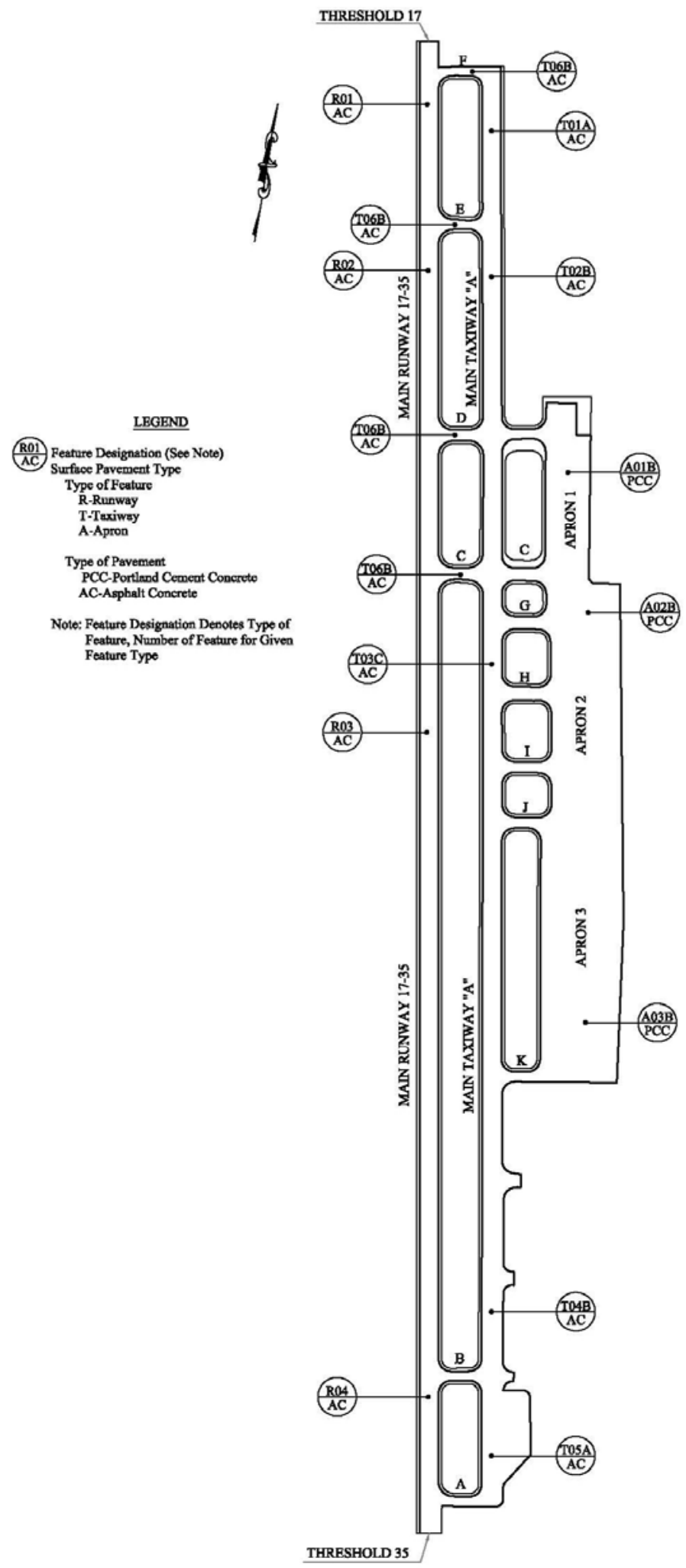

Figure (4): Feature Identification for Aswan Airfield Pavements. 


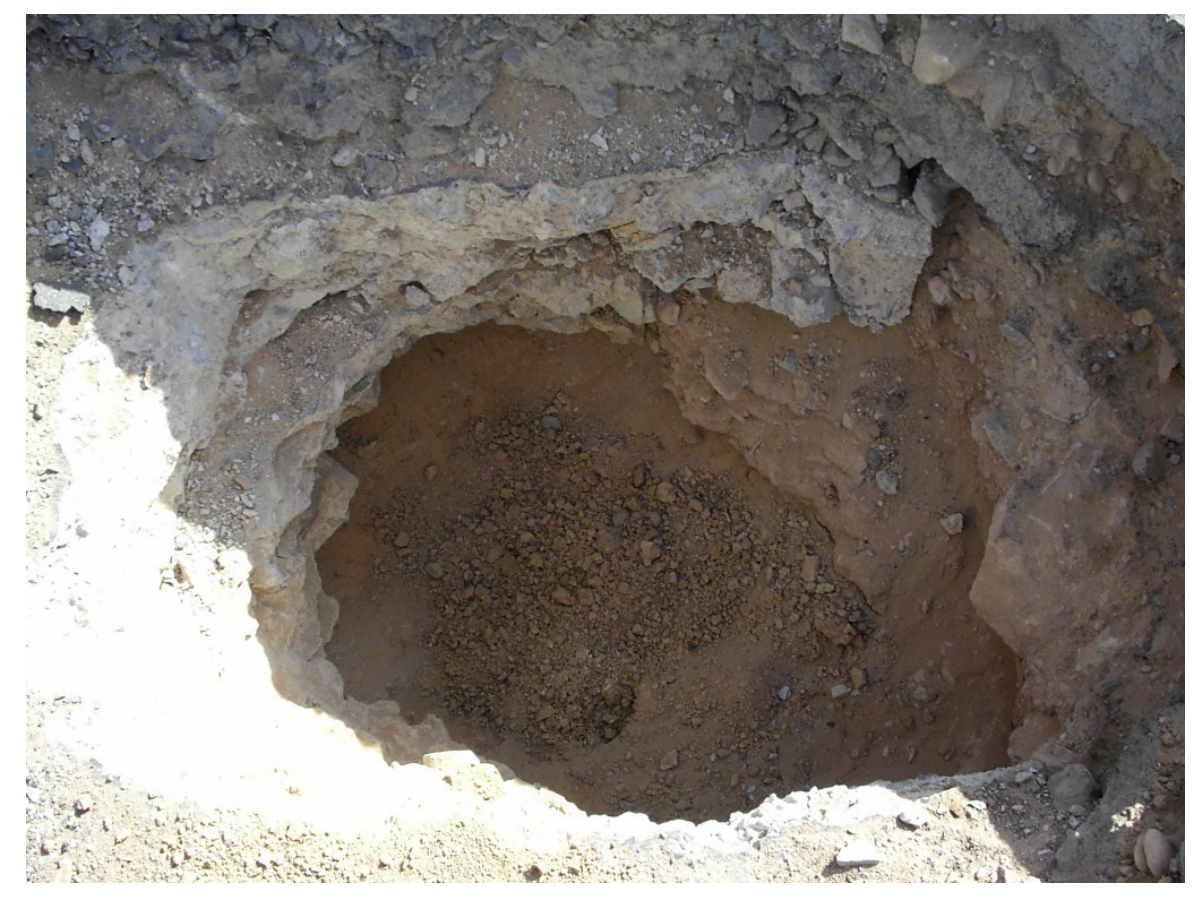

Figure (5): Pavement Layers for Main Runway 17-35 of Aswan Airport.

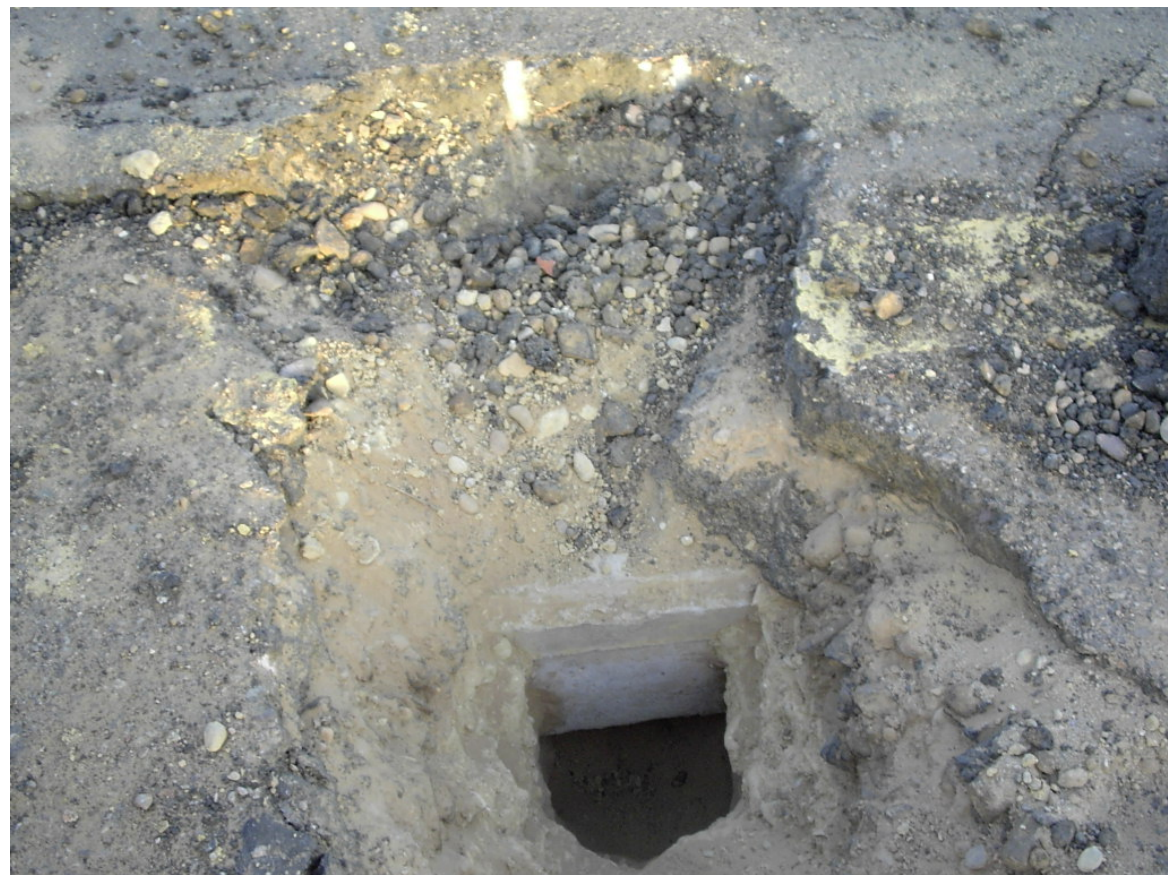

Figure (6): Pavement Layers for Main Taxiway of Aswan Airport. 


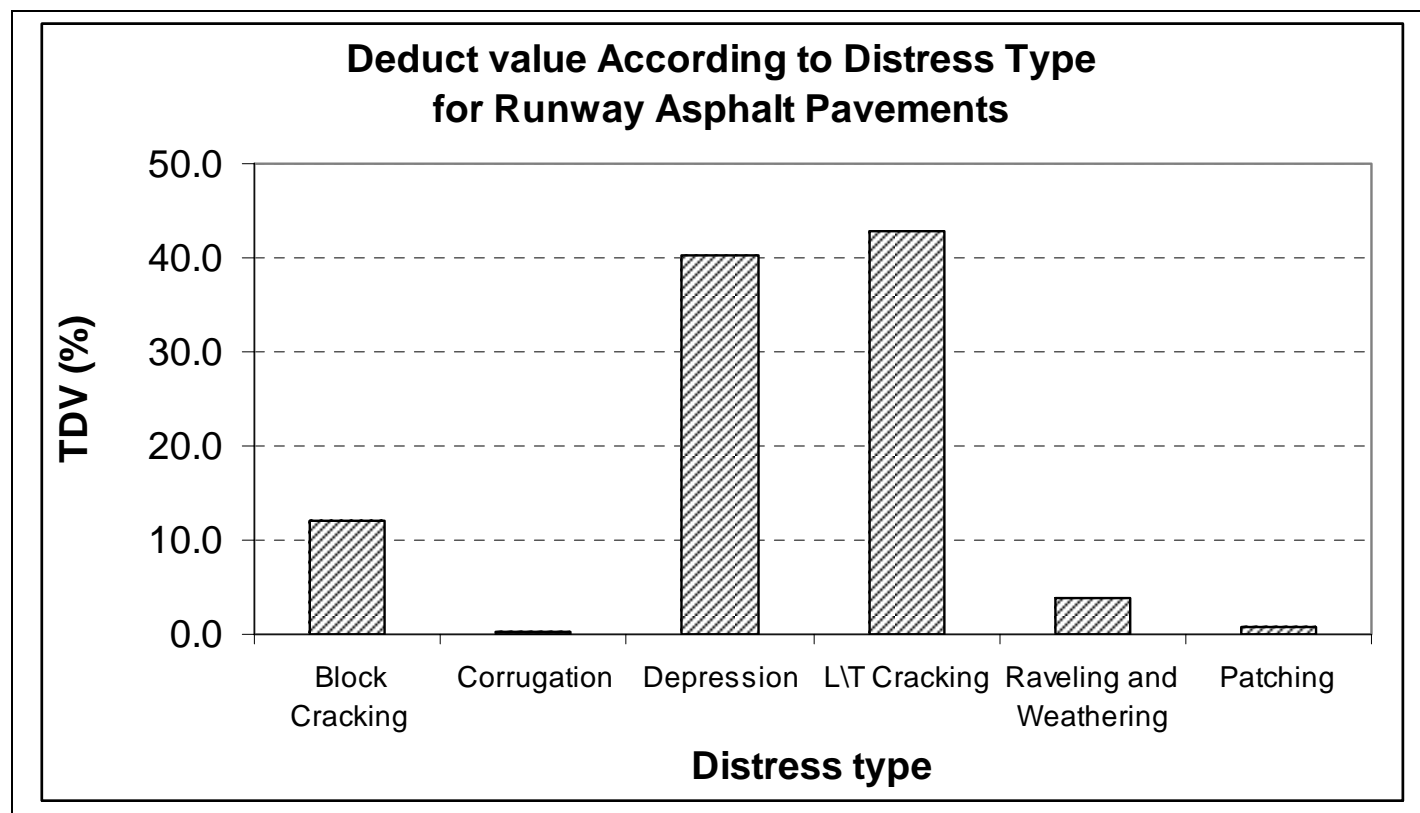

Figure (7) Distress Contribution in Overall Condition for Runway Asphalt Pavements, Survey on 15-5-2005.

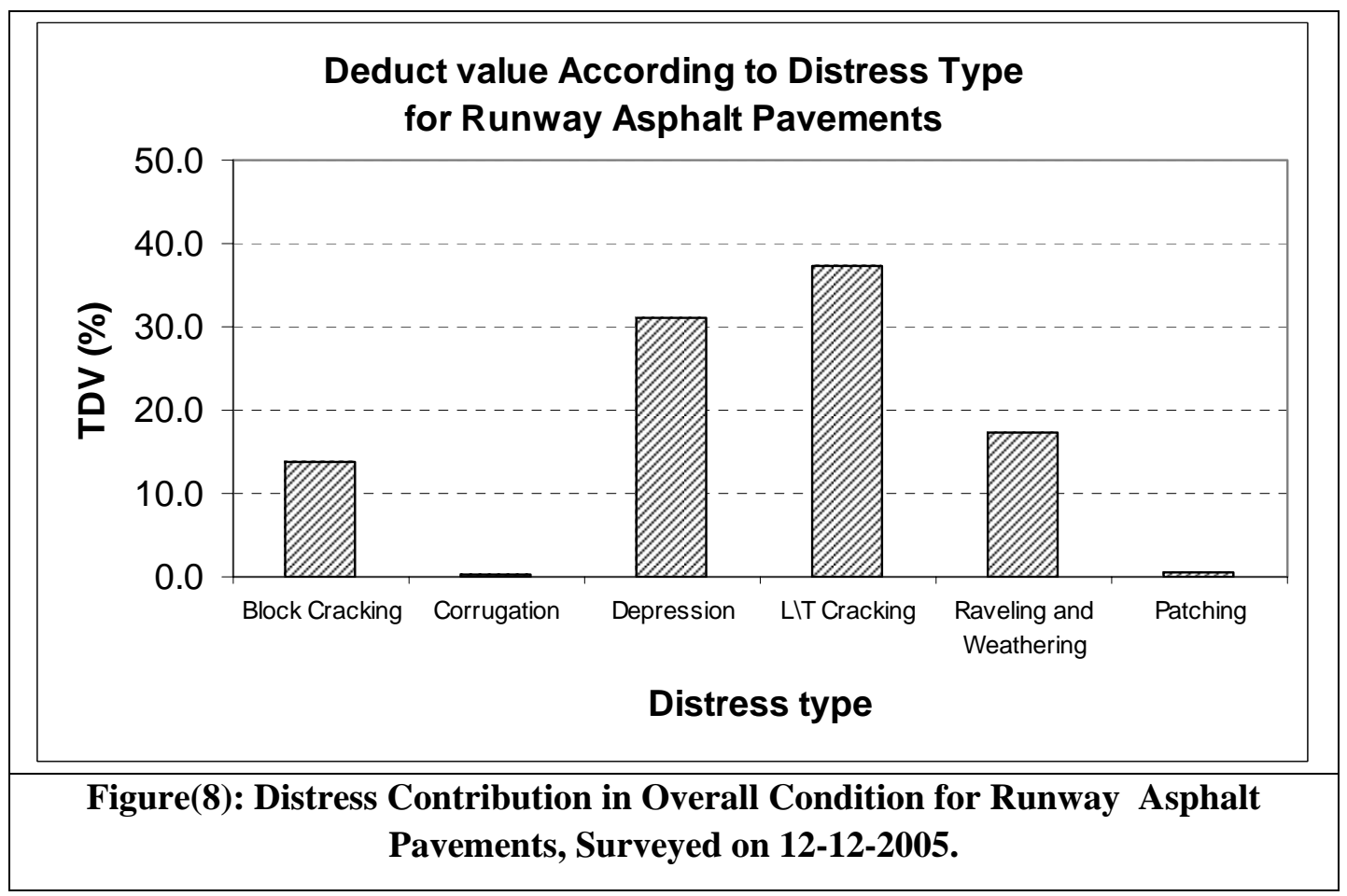



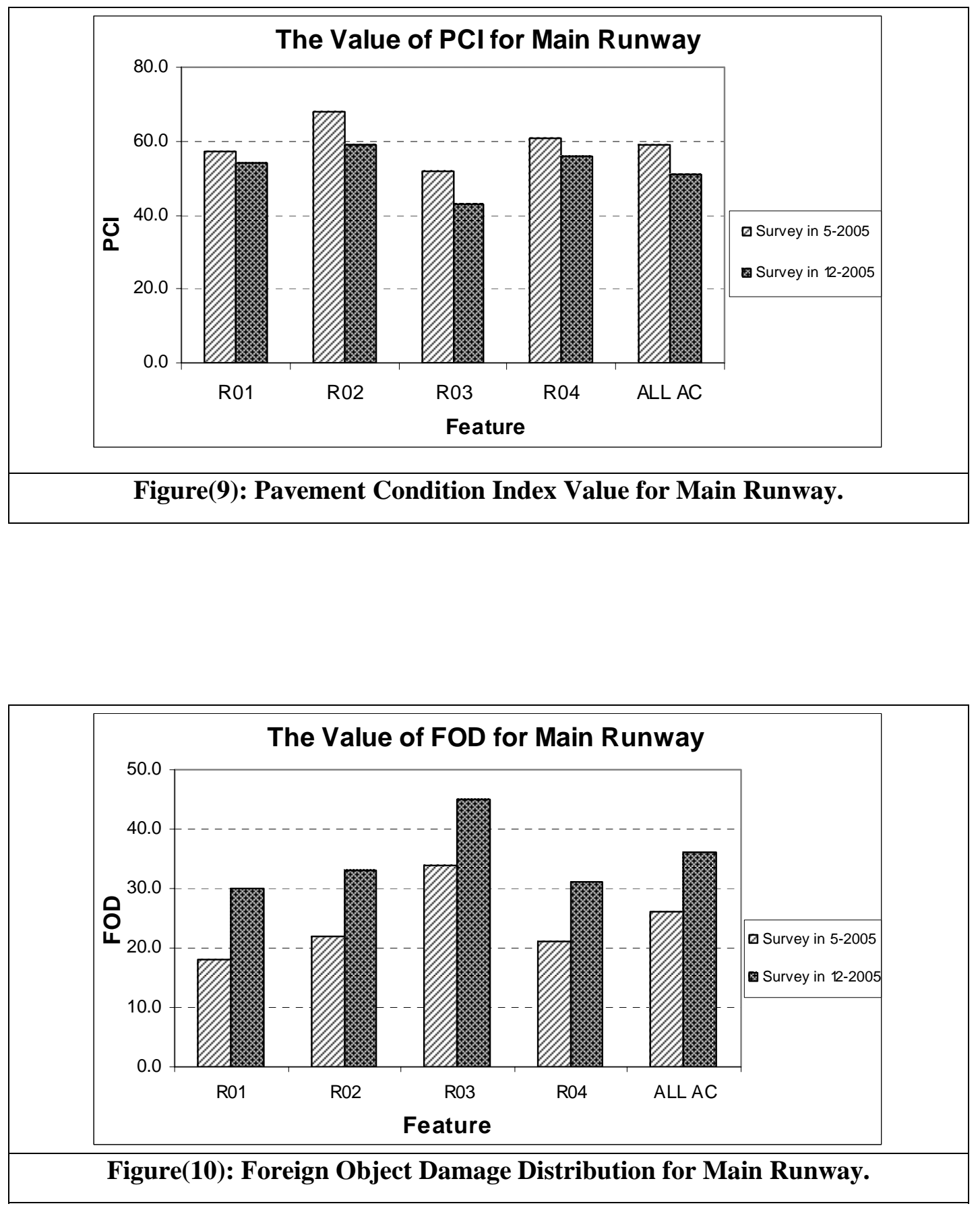

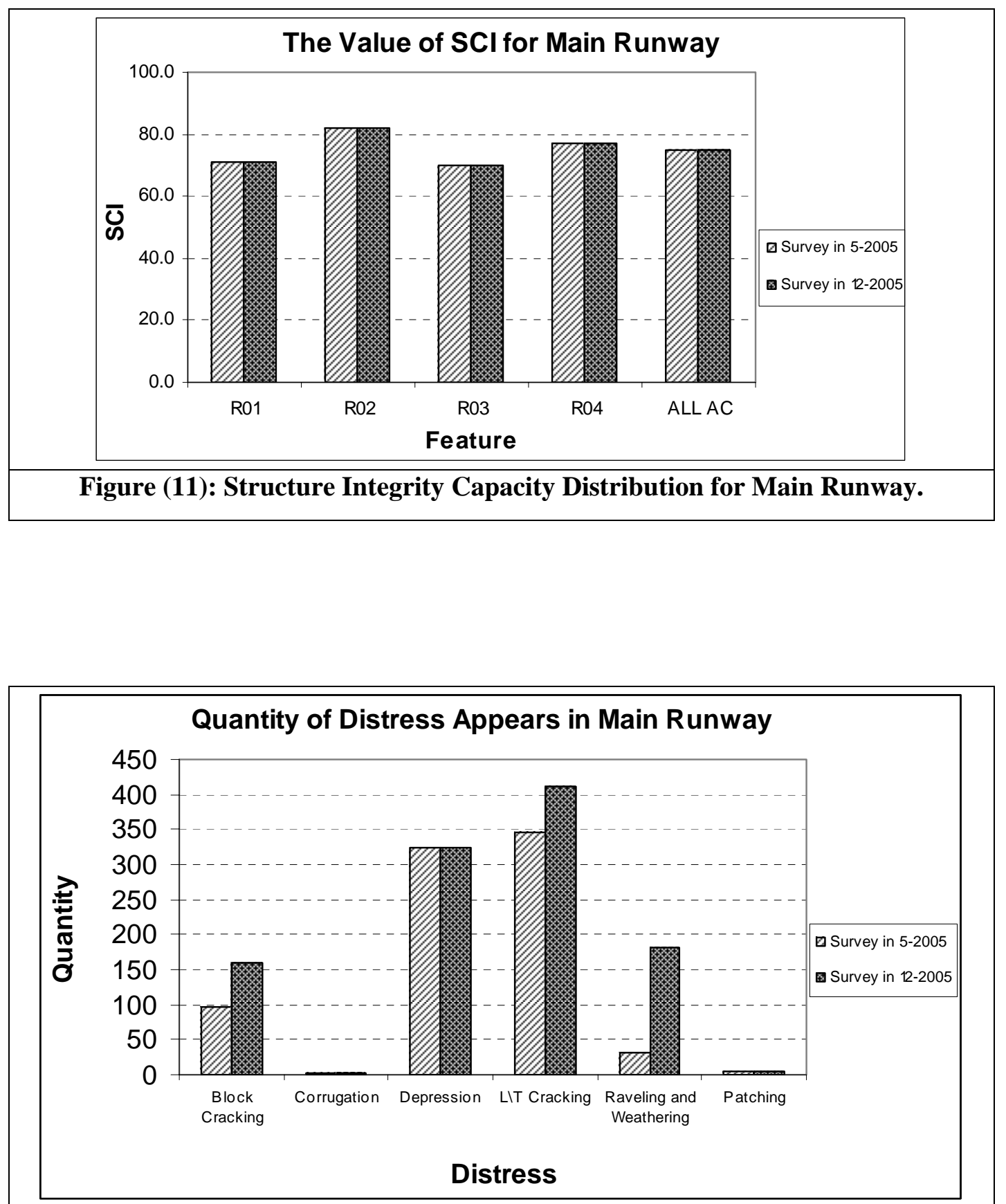

Figure (12): Quantity of Distress Appears in Main Runway. 


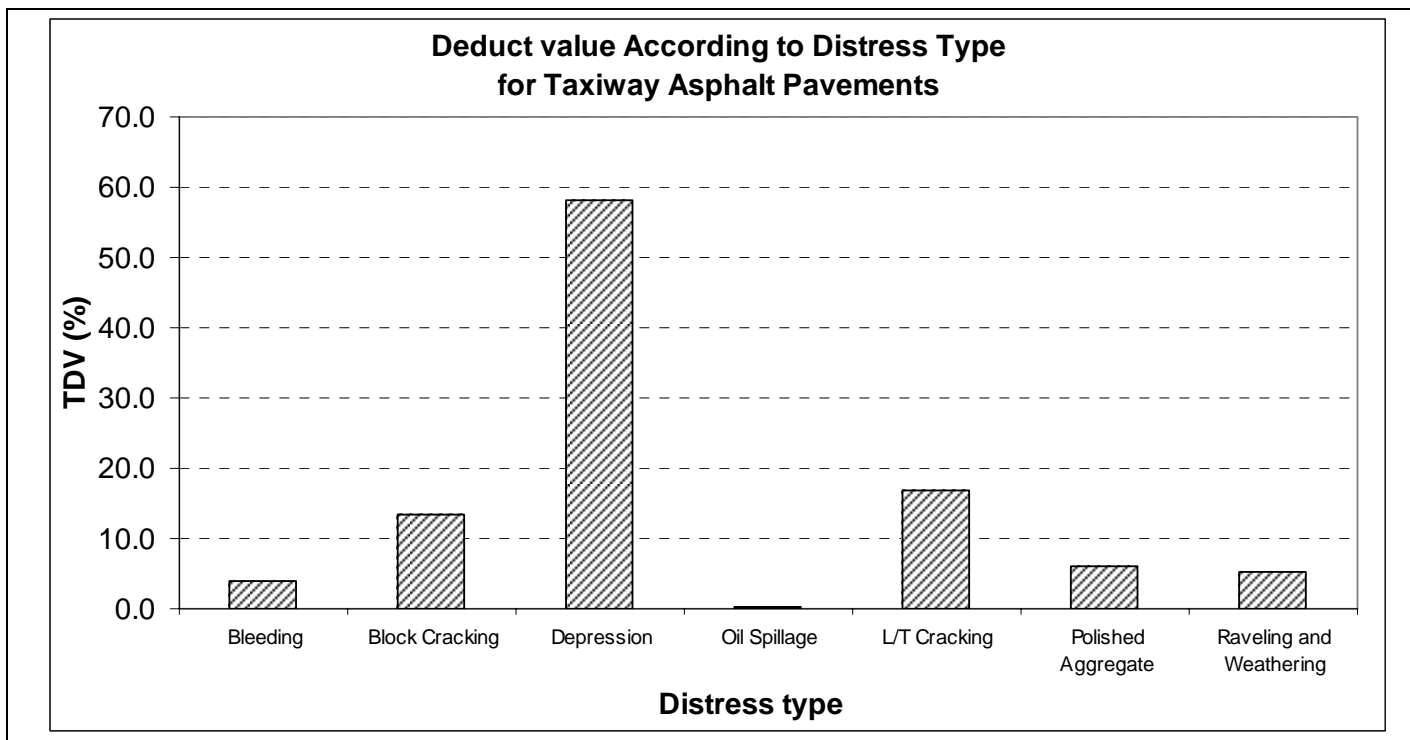

Figure (13): Distress Contribution in Overall Condition for Taxiway Asphalt Pavements. 